\title{
Balkanologie
}

Balkanologie Revue d'études pluridisciplinaires

Vol. III, n² | 1999

Volume III Numéro 2

\section{Roux (Michel), Le Kosovo. Dix clés pour comprendre}

Paris : La Découverte (Sur le vif), 1999, 127 p. [Bibliogr. Chrono. Sites

internet].

Patrick Michels

CpenEdition

Journals

Édition électronique

URL : http://journals.openedition.org/balkanologie/2195

DOI : $10.4000 /$ balkanologie.2195

ISSN : 1965-0582

Éditeur

Association française d'études sur les Balkans (Afebalk)

Édition imprimée

Date de publication : 1 décembre 1999

ISSN : 1279-7952

Référence électronique

Patrick Michels, «Roux (Michel), Le Kosovo. Dix clés pour comprendre », Balkanologie [En ligne], Vol. III, n² | 1999, mis en ligne le 22 juin 2010, consulté le 17 décembre 2020. URL : http://

journals.openedition.org/balkanologie/2195; DOI : https://doi.org/10.4000/balkanologie.2195

Ce document a été généré automatiquement le 17 décembre 2020.

(c) Tous droits réservés 


\title{
Roux (Michel), Le Kosovo. Dix clés pour comprendre
}

\author{
Paris : La Découverte (Sur le vif), 1999, 127 p. [Bibliogr. Chrono. Sites \\ internet].
}

\section{Patrick Michels}

\section{RÉFÉRENCE}

Roux (Michel), Le Kosovo. Dix clés pour comprendre, Paris : La Découverte (Sur le vif), 1999, 127 p. [Bibliogr. Chrono. Sites internet].

1 Une fois de plus, M. Roux publie un travail de qualité, plus proche du travail scientifique d'analyse que de la propagande pro ou anti très courante dans ce qui s'est écrit sur la Yougoslavie et l'“ex" ses dix dernières années.

2 Synthétique, clair et précis, simple, l'ouvrage se veut abordable par tous ceux que les événements troubles qui se sont déroulés dernièrement au Kosovo ont interpellés. Une sorte de mise au point. D'analyses sérieuses en perspectives explicatives, l'opus ne se contente pas d'éclaircir ce qui s'est déroulé, mais également les conséquences de la guerre de l'OTAN contre la "Yougoslavie" sur de nombreux pays (cf. chapitre 10).

3 Mais, comme souvent, on peut ne pas être d'accord avec toutes les assertions de M. Roux (peut-être à cause de la simplification nécessaire à l'édition d'un livre grand public ?) : les militants et dirigeants de l'UCK n'œuvrant pas pour la réalisation de la "Grande Albanie". Ce n'est pas parce que les Albanais (de Serbie, de Macédoine, d'Albanie, du Monténégro, selon leur classe sociale, ...) sont divisés sur la question que l'organisation terroriste n'a pas d'avis tranché. Le géographe-historien montre bien l'enchaînement qui a conduit à la politique du pire, les Albanais du Kosovo n'ayant plus vraiment le choix. On aurait aimé une analyse des conflits entre Ligue Démocratique du Kosovo et Armée de Libération du Kosovo, qui, malheureusement, se situait en dehors du sujet de ce livre. 
4 Tout au long de son travail, M. Roux montre bien comment « après ce qui s'est passé entre mars et juin 1999, une réintégration réelle du Kosovo en Serbie est impossible». On saluera sa terminologie précise, tout en regrettant qu'il ait adopté, concernant la Bosnie-Herzégovine, celle prônée par P. Garde, dont la finalité, même involontaire, est de faire des Croates et Serbes de Bosnie des allogènes ${ }^{1}$. On regrettera également quelques vétilles : "l'éclatement de l'ex-Yougoslavie ", et non de la Yougoslavie, en 1991 ; le double “jj” de Djakovica (Đjakovica), et la disparition des pages 77 à 80, imputables à la relecture et à l'imprimeur ${ }^{2}$. On s'interrogera plus sur le fait que les critiques croates vis-à-vis de la décentralisation soient passées sous silence (p. 31). Mais, là aussi, ces défauts sont mineurs, et ne nuisent aucunement à la qualité du travail fourni. Enfin, on appréciera la présentation de sites internet liés, sinon dédiés, au Kosovo.

\section{NOTES}

1. P. Garde avait proposé, sur le modèle souhaité par les élites musulmanes de BosnieHerzégovine, que les Musulmans soient désignés par "Bosniaques", terme en cours jusqu'alors pour désigner tous les habitants de la Bosnie-Herzégovine qui devenaient (et deviennent) les "Bosniens", appellation plutôt rare en Occident. Rare mais pas inexistante: par Bosnien, le traducteur de Gellner (Ernest), Nations et nationalisme, Paris, Payot, 1989 (p. 109) faisait mention des Musulmans et non des habitants de la Bosnie-Herzégovine.

2. Nous-mêmes sommes très friands de ce genre d'erreurs.

\section{AUTEURS}

\section{PATRICK MICHELS}

